\title{
LETTERS
}

\section{COVID-19 outbreak measures may indirectly lead to greater burden on hospitals}

We thank Dr. Laupacis for his solemn yet hopeful editorial on coronavirus disease 2019 (COVID-19). ${ }^{1}$ While the focus on acute care and public health services is justified, we posit that chronic disease management must continue during this pandemic. ${ }^{2}$

Social distancing decelerates viral transmission, but could have substantial adverse effects on older Canadians living with frailty and multimorbidity. ${ }^{3}$ Many health care providers are prioritizing "urgent" conditions, downsizing access for frail older individuals whose conditions are considered "nonurgent." Social distancing is likely to affect both formal and informal care and lead to loneliness, depression, anxiety, accelerated functional and cognitive decline, and falls and fractures. ${ }^{4}$ A distressed caregiver can quickly become overburdened if supports are reduced, with respite being sought in the emergency department. Those with chronic cardiac or lung disease may see mild symptoms worsen to the point of requiring hospital admission. ${ }^{4}$ Vulnerable older adults who are discharged from home and community services may experience exacerbation of conditions that had previously been stable with appropriate community supports. If admitted to hospital, these individuals will be further isolated and face a greater risk for delirium and functional decline, leading to increased length of stay and need for home care, rehabilitation or institutionalization upon discharge. ${ }^{5}$

Thus, outbreak measures may in fact lead to greater burden on hospitals.

Effective chronic disease management must be part of our pandemic response. Geriatric assessments can reliably be delivered virtually, preventing acute care usage and ensuring that social distancing is maintained. ${ }^{6}$ Clinical decision support with interRAI (www.interrai.org) assessments deployed in virtually all Canadian home and long-term care sectors can successfully guide "telegeriatrics."

\section{George A. Heckman MD}

Geriatrician, Schlegel-University of Waterloo Research Institute for Aging, Waterloo, Ont.

\section{Margaret Saari RN PhD}

Postdoctoral fellow, SE Health, Markham, Ont.

\section{Caitlin McArthur MScPT PhD}

Postdoctoral fellow, GERAS Centre for Aging Research, St. Peter's Hospital, Hamilton, Ont.

\section{Nathalie I.H. Wellens SLP PhD}

Program manager, coRAl; research fellow, Centre Qualité et Systèmes, Department of Public Health Services and Social Affairs,

\section{Canton Vaud, Switzerland}

\section{John P. Hirdes PhD}

Health services researcher, University of Waterloo, Waterloo, Ont.

Cite as: CMAJ 2020 April 6;192:E384. doi: $10.1503 / \mathrm{cmaj} .75230$

\section{References}

1. Laupacis A. Working together to contain and manage COVID-19. CMAJ 2020 Mar. 17 [Epub ahead of print]. doi: 10.1503/cmaj.200428.

2. Scott IA. Chronic disease management: a primer for physicians. Intern Med J 2008;38:427-37.

3. Vetrano DL, Palmer K, Marengoni A, et al. Joint Action ADVANTAGE WP4 Group. Frailty and multimorbidity: a systematic review and meta-analysis. J Gerontol A Biol Sci Med Sci 2019;74:659-66.

4. Wodchis WP, Austin PC, Henry DA. A 3-year study of high-cost users of health care. CMAJ 2016;188:182-8.

5. Surkan MJ, Gibson W. Interventions to mobilize elderly patients and reduce length of hospital stay. Can J Cardiol 2018;34:881-8.

6. Martin-Khan MG, Edwards H, Wootton R, et al. Reliability of an online geriatric assessment procedure using the interRAI acute care assessment system. J Am Geriatr Soc 2017;65:2029-36.

7. Heckman G, Gray LC, Hirdes J. Addressing health care needs for frail seniors in Canada: the role of interRAI instruments. CGS J CME 2013;3:8-16.

Competing interests: All authors are members of interRAl, a not-for-profit international scientific organization. They are writing on behalf of interRAI. 